\title{
The Clock Proxy Auction for Allocating Radio Spectrum Licenses
}

\author{
A. Mochon · Y. Saez • J. L. Gómez-Barroso • \\ P. Isasi
}

\begin{abstract}
The combinatorial clock-proxy auction is analyzed as a selling mechanism of a portion of the "digital dividend" in an European country. We assumed bidders with bounded rationality making their bidding decisions based on a system of recommendation that learns from the environment. The auction outcome when all bidders follow the proposed strategies was compared with the efficient outcome of the auction. Although significant differences were found in the seller's income, no significant variations were found in the distribution of spectrum licenses among bidders.
\end{abstract}

Keywords Clock-proxy auction · Radio spectrum · Genetic algorithms · Simulations

\section{Introduction}

The process of digitizing television broadcasting signals is already under way around the world. Indeed, many countries have established an early deadline for the "analogue blackout". Transmission of existing television channels in a digital format requires a much smaller spectrum than does an analogue broadcast. Thus digital broadcasting makes it possible to free up a sizeable portion of the spectrum for new services in spite of new channels being added. These "new" available resources are referred to as the "digital dividend".

\footnotetext{
A. Mochon (凶) · J. L. Gómez-Barroso

Department of Applied Economics, UNED, $\mathrm{P}^{o}$ Senda del Rey, 11, 28040 Madrid, Spain e-mail: amochon@cee.uned.es 
The radio electric spectrum is a scarce resource, a resource for which demand is growing quickly as the proliferation of innovative services that require spectrum for operating continues. Furthermore, the UHF band offers a combination of coverage and capacity (bandwidth) that makes it suitable for a wide range of different uses. Therefore, allocation decisions of the digital dividend will involve trade-offs between different potential uses. Traditionally, several procedures have been used to deal with this task (lotteries, beauty contests, first-come-first-served, etc.) but none of them simultaneously achieves the objectives of transparency, revenue maximization, and efficiency. In this context, auctions turn out to be the best alternative, as they represent a transparent method of allocation that promotes competition and reduces corruption. ${ }^{1}$

When assigning many related goods, such as radio spectrum frequency band segments, bidders' values for an item might depend on the number of items already won. Hence, subadditive and superadditive values or synergies among licenses arise (Ausubel et al. 1997). In these circumstances, allowing bidders to make offers on combinations of items, known as packages or combinatorial auctions, is one of the best possible allocation mechanisms because it permits bidders to fully express their preferences. A variety of different combinatorial auction formats can be selected. Probably, the most popular auction format for allocating radio spectrum is the simultaneous ascending auction (Cramton 2002). It has been used by the US Federal Communication Commission (FCC), Ofcom in the UK, the Australian Communications and Media Authority in Australia, the Federal Network Agency for electricity, gas, telecommunications, post and railway in Germany and others.

Recently, a new combinatorial auction format has been proposed for the sale of spectrum licenses: the clock-proxy auction (Ausubel et al. 2006). According to Cramton (2007), the clock-proxy auction is an excellent alternative when packaging issues are important and bidders exhibit complex preferences structures of substitute and complement goods, just as it happens in the spectrum license market. In fact, this auction format has already been successfully used in a spectrum auction for Trinidad and Tobago in 2005, and it is being considered as an alternative for awarding the digital dividend in the UK (see Ofcom 2007). Nevertheless, research of the clock-proxy auction in still quite incomplete.

The aim of this work is to investigate the clock-proxy auction as a selling mechanism in the spectrum license market. To achieve this aim, we built a realistic model of a European spectrum license market and a clock-proxy auction simulator. In this application, the most difficult task was to simulate the bidders' behavior. Finding the best strategy in the selected environment using enumeration is computationally infeasible. This is because there are a large number of strategies, and all strategies depend on bidders' preferences and rivals' strategies (Reeves et al. 2005). To deal with this problem, we assume bidders with bounded rationality making their bidding decisions based on a genetic algorithm system. This system learns from the environment and improves bidding behavior with experience of a large number of auctions. Experimental and

\footnotetext{
1 Bulow and Klemperer (2009) compared the results of allocating public goods by means of auctions concluding that "the straightforward, level-playing-field competition that a simple auction creates is usually more profitable for a seller than a sequential procedure that sometimes attract more bidders, but prevents direct, simultaneous competition among all participants on equal terms".
} 
validation tests were carried out to provide evidence of the appropriateness of the proposed strategies. For a given environment, this experimental analysis was done with different types of bidders and with changeable valuations and strategies. Finally, the auction outcome when all bidders follow the genetic algorithm-based system was also studied in terms of allocation and seller revenue and compared with the efficient outcome of the auction.

The remainder of this article is structured as follows. Section 2 describes previous work on combinatorial auctions, focusing on the specific combinatorial auction format being studied: the clock-proxy auction. The description of the specific model built for the experiments - that is, the characteristics of the digital dividend sale (radio spectrum to be auctioned and participant bidders) - is explained in Sect. 3. The bidding decision system developed and the bidding strategies tested both in the clock phase and in the proxy phase are described in detail in Sect. 4. The results are analyzed and discussed in Sect. 5. Finally, in last section, the main conclusions and future work are outlined.

\section{Combinatorial Auctions: The Clock-Proxy Auction}

Some research has studied the problem of simulating bidding behaviors in combinatorial auctions. ${ }^{2}$ The study of Parkes (1999) and Parkes and Ungar (2000a) describes a combinatorial ascending-price auction called $i$ Bundle that assumes bidders follow a myopic best-response bidding strategy in response to current allocation and ask prices. Myopically rational agents maximize their utility with no anticipation of their rivals' strategies. Hence, bidders bid as low as possible until the ask price is greater than the bidders' valuation of the bundle. These authors also tested this strategy in an $i$ Bundle auction with proxy agents and price-adjustment (Parkes and Ungar 2000b). Other researchers have developed autonomous bidders that interact in multiple, simultaneous auctions for related goods (Stone et al. 2003). These authors calculate optimal bids by predicting eventual prices of goods based on previous auctions. They use a machinelearning approach (a boosting-based algorithm) to examine previous prices according to certain basic features, such as the number of minutes remaining in the game, current ask price for items that have not closed, and so on [further information about price prediction can be found in Wellman et al. (2004)]. One important related study is that described in Reeves et al. (2005). These authors study the simultaneous ascending auction in the presence of complementarities when bidders pursue particular strategies. They select a set of candidate strategies, called the sunk-aware strategy family. A sunk-aware agent bids as if the incremental cost for the items currently up for sale is somewhere between zero $(k=0)$ and the current bid price $(k=1$, or the straightforward bidding strategy; it is also referred to as myopic best response), with $k$ as the sunk-awareness parameter. Bidders select the sunk-awareness parameter according to information from the current auction round, thus acting as reflex agents responding to prices and winning items. The strategies' performances are evaluated against

\footnotetext{
${ }^{2}$ Hailu and Thoyer (2010) analysed bidding strategies in multi-unit multiple-bid auctions by means of computational experiments.
} 
each other through an evolutionary game statistical simulation, and poor strategies are weeded out. The authors' main conclusion emphasizes the feasibility of exploring strategic issues in a simultaneous auction through the parameterization of a strategy space, sampling-based simulation and evolutionary search. Moreover Avenali and Bassanini (2007), employed automated agents in a combinatorial first-price, multi-round auction that posits a model of bidders' beliefs about their opponents. In this model, the highest bids in each round are stored and subsequently used by players to compute a probability density function for the valuation of each bundle that has been bid upon by rivals. Each bidder maximizes his/her profits considering the expected offers for the next round.

The clock-proxy auction (Ausubel et al. 2005, 2006) is a combinatorial auction with two phases. In the first phase, or clock phase, bidders ask for a package of items in a multi-round clock auction. Afterwards, in the proxy phase, the auction ends with a final proxy round. Consider that there are $n$ bidders $(i=1, \ldots, n)$ participating in a radio spectrum auction. Before the auction starts, the auctioneer describes the bands $(\Omega=1, \ldots, m)$ to be auctioned: different types of bands $(m \geq 1)$, the number of lots included in each type of band, ${ }^{3}$ the bandwidth of the lot and the initial round price per lot. Then the auction begins. Since the clock-proxy auction is a sophisticated model, Fig. 1 includes a flowchart diagram which summarizes the entire process.

\subsection{The Clock Phase}

When the clock phase begins, the auctioneer announces a price vector indicating the price per lot of each band in that round $(r):\left(P_{1}^{r}, \ldots, P_{m}^{r}\right)$. Then each bidder $i$ submits one single package bid by selecting a quantity vector $Q^{i, r}=Q_{1}^{i, r}, \ldots, Q_{m}^{i, r}$ indicating the number of lots of each band that he is willing to buy at the current prices in round $r$. The total price that bidder $i$ is offering for his/her package in round $r$ is calculated according to Eq. 1:

$$
P^{i, r}=\sum_{k=1}^{m} P_{k}^{r} Q_{k}^{i, r}
$$

A package bid in round $r$ of the clock phase is a tuple $B^{i, r}=\left(Q^{i, r}, P^{i, r}\right)$, where $Q^{i, r} \subset \Omega$ is the package (or single item) selected by bidder $i$ and $P^{i, r}$ is the price for the complete package (or single item). With all the bids submitted in one round, the auctioneer determines whether the sum of the requested quantities per band is less than or equal to the available lots in each band $\left(\bar{Q}_{k}\right)$; see Eq. 2 :

$$
\sum_{i=1}^{n} Q_{k}^{i, r} \leq \overline{Q_{k}}
$$

\footnotetext{
${ }^{3}$ Lots in the same band are identical or close substitutes. Lots among different bands exhibit differences.
} 


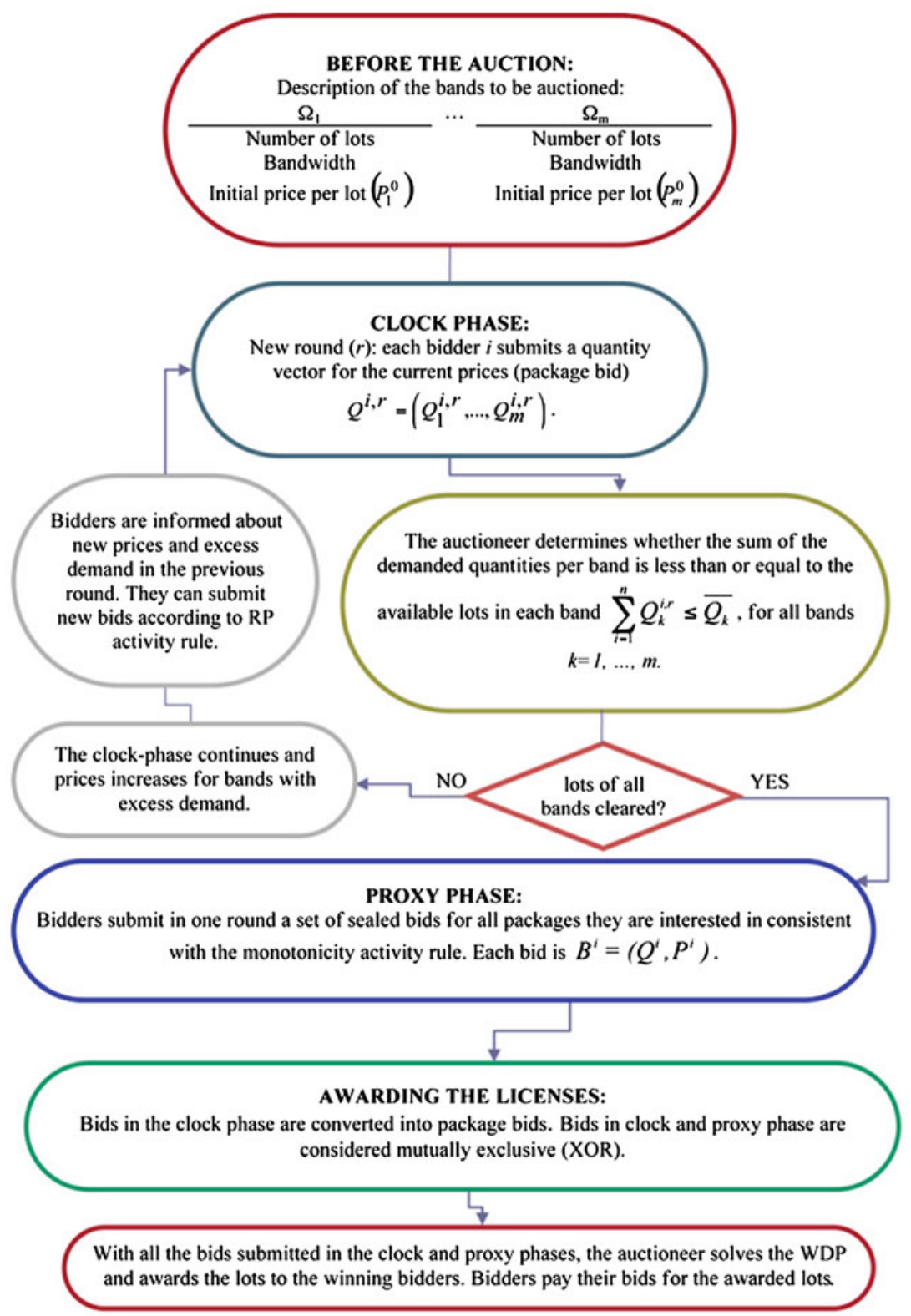

Fig. 1 Flow-chart diagram of the clock-proxy auction mechanism 
The auctioneer then increases prices for bands with excess demand, and bidders submit bids again in a new round. Bidders are informed about new prices and quantities of excess demand in the previous round and can submit new bids in the round $r+1$. This process continues until there is no band with excess demand. The clock phase finishes when all band lots have been cleared.

To avoid insincere bidding in the clock phase, an activity rule between rounds must be determined. ${ }^{4}$ Ausubel et al. (2006) proposed the revealed-preference (RP) activity rule for which a quantity vector $Q^{i, r}=\left(Q_{1}^{i, r}, \ldots, Q_{m}^{i, r}\right)$ is a valid bid only if the inequality (Eq. 3) holds:

$$
\left(P^{r}-P^{s}\right)\left(Q^{i, r}-Q^{i, s}\right) \leq 0, \quad \text { for all } s<r
$$

For the case of a single good, the RP activity rule requires that as prices goes up quantity cannot increase. Nevertheless, when there are many goods the RP gives bidders some flexibility. In the presence of substitutes goods it allows bidders to shift quantities toward the relatively cheap product. In the case of perfect complements, as prices increases the bidder can maintain the same demand or decrease the quantities in the desired ratio, but he/she can never increase quantities. Hence, the RP rule works properly in the presence of substitutes and complements goods.

In the experiments done in this research, the bidders' behavior simulated in the clock phase (described in Sect. 4), always satisfies the RP activity rule, as bidders bid on the most profitable package in every round (Cramton 2007).

\subsection{The Proxy Phase or Sealed Bid Phase}

Once the clock phase is over, the auction ends with a final proxy round in which bidders report their offers to a proxy agent who bids on behalf of the real bidder. In this study, we assumed that proxy bidding is mandatory and unchangeable. Thus, we have solved the proxy round through a sealed-bid package auction. ${ }^{5}$ In this last round, bidders are able to submit sealed bids for all the packages they are interested in. Each bid made by bidder $i$ is a pair $B^{i}=\left(Q^{i}, P^{i}\right)$, where $Q^{i} \subset \Omega$ is a package of lots and $P^{i} \geq 0$ the amount that bidder $i$ offers for that package $Q^{i}$. This phase allows bidders to make offers for packages of lots they did not bid for in the previous phase, and to increase the offers made in the clock phase. The set of sealed bids made in this phase by bidder $i$ must satisfy the following constraint: if a bidder submits a bid for a selection of lots already included in the clock phase, the total offer of the sealed bid must exceed the amount of any bid submitted by that bidder in the clock phase (monotonicity activity rule).

\footnotetext{
4 The most frequent activity rule in clock auction is monotonicity in quantity: as prices goes up, quantities cannot increase. A weaker activity rule is a monotonicity of aggregate quantity across a group of lots.

5 "An auction process with mandatory proxy bidding -and in which a bidder is not allowed to make changes to the flexible bid information that is used by its proxy agents- is observationally equivalent to a sealed-bid auction" (Ausubel et al. 2005).
} 


\subsection{Awarding the Items}

All bids submitted in the clock and proxy phases are considered together to compute the winners of the auction. Hence, bids submitted in the clock phase $B^{i, r}=\left(Q^{i, r}, P^{i, r}\right)$ are converted into package bids. However, winning bidders can only win with a single bid, that is, bids are mutually exclusive and are described using XOR bidding language. With all bids submitted by bidders in both phases, the auctioneer must determine the feasible allocation of lots that maximizes his/her revenues, which means solving the Winner Determination Problem (WDP). In this auction, as several bands with different number of lots have been auctioned, the feasibility constraint implies that the total quantity vectors in the winning bids per band must not exceed the available quantities. According to Ausubel et al. (2005), the specification of the WDP for these requirements correspond to the maximization problem described in Eq. 4:

$$
\text { Maximize } \sum_{i=1}^{n} \tilde{P}^{i} \quad \text { subject to : }
$$

- At most, one winning bid $\left(\tilde{Q}^{i}, \tilde{P}^{i}\right)$ is selected for each bidder $i=1, \ldots, n$;

- If bidder $i$ is a winning bidder, then $\tilde{P}^{i}$ is the price in his/her winning bid;

- If bidder $i$ is a losing bidder, then $\tilde{P}^{i}=0$; and

- $\sum_{i=1}^{n} \tilde{Q}_{k}^{i} \leq \bar{Q}_{k}$ (feasibility constraint)

Solving the WDP is a NP-complete problem (Sandholm 2002). Hence, advanced computational techniques must be used to deal with this task. In this study, the A* search algorithm, based on a branch on bids (BOB) formulation, was used. ${ }^{6}$ After solving the WDP, the auctioneer determines the winning bids and bidders pay their bids for the awarded lots, according to the pay-your-bid pricing rule. ${ }^{7}$

\section{The Selected Environment: Selling the Digital Dividend in a European Country}

Historically, regulators have decided who may use the spectrum, what services they may provide, and what technologies they may use. However, spectrum management is changing to put greater emphasis on market mechanisms (Feijóo et al. 2009). The digital dividend offers an ideal opportunity to introduce criteria in an attempt to increase

\footnotetext{
6 The A* algorithm is a widely-used informed search technique mostly used in path-finding and graph traversal. In the proposed formulation, a tree of bids is built and searched with this algorithm (for more details about this implementation, see Saez et al. 2008).

7 The pay-your-bid pricing rule is a simple way for bidders to understand the final payment. Nevertheless, the bidder-optimal core pricing rule could also be implemented, see Day and Raghavan (2007). As Ausubel and Cramton (2008) stated, with the bidder-optimal core pricing rule (also called the second-price rule) "payments are determined so as to yield outcomes that are optimal from the bidders' perspective among all outcomes that satisfy the core constraints. Core constraints require that the winning assignment maximizes total value, and assure that there is no coalition of bidders that can object that they bid more than the announced payments but did not win".
} 
efficiency in the use of the spectrum. The USA has already auctioned part of its digital dividend. Moreover, some European countries have announced their intention of allocating this resource through auctions. The use of auctions is not unknown in the telecommunications sector. The essential difference auctioning the digital dividend lies in service neutrality: previous allocation auctions have served to select operators, but services and technologies for which the specific band was to be used were strictly regulated. That has not been the case for the digital dividend auction in the USA, and many other countries would probably follow this scheme. ${ }^{8}$

This model aims to simulate a digital dividend of a size that could fit in most European countries. The total spectrum to be auctioned corresponds to $96 \mathrm{MHz}$, which is divided into three types of bands $(m=3)$. Each type of band is apportioned in the following lots: $\Omega_{1}=1$ lot of $40 \mathrm{MHz}, \Omega_{2}=2$ lots of $16 \mathrm{MHz}$ and $\Omega_{3}=3$ lots of $8 \mathrm{MHz}$.

The next step is to model bidders participating in the auction. Almost all service and application providers using the radio electric spectrum would be interested in participating in sharing this "newly available" spectrum in a band as appealing as UHF. Therefore, the list of possible services the digital dividend could be allocated to is long: digital terrestrial television, mobile multimedia, mobile communications; low power device-related services, such as medical telemetry, Radio Frequency Identification (RFID) or Near Field Communications (NFC); and noncommercial services, such as defense, security, emergencies or other public services. However, in a commercial auction, such as the one to be simulated (with licenses awarded for a national coverage and 8-40 MHz lots), only the three services first mentioned could have actual possibilities of obtaining a spectrum: television (new channels in standard or high definition), multimedia services (interactive television, on-demand video, music, radio) for mobile devices, and mobile communications (high-bandwidth data services and voice). The simulation exercise models the participation of seven different bidders. These bidders may be interested in operating in more than one market and may exhibit both complements and substitute preferences among licenses. The values participants place on each lot have been adapted from the estimations made by the British regulator (Ofcom) to identify incremental producer and consumer value generated from the use of spectrum (Ofcom 2006). These values are the maximum amount each bidder will be willing to pay for each lot. ${ }^{9}$ For each possible use of the spectrum, a maximum and

\footnotetext{
${ }^{8}$ Moreover, Bykowsky et al. (2010) show the validity of market mechanisms (auctions) even to allocate the spectrum between licensed and unlicensed use. In such an auction, participating firms would fall into two distinct categories as a result of differences in their business models. The business model of "traditional" firms involves constructing the necessary infrastructure and earning a return on that investment based on revenue obtained from subscribers. Consequently, they strongly prefer to acquire a spectrum with licensing rules that enable them to exclude nonpayers and to receive protection from harmful interference. However, another type of bidder would have a preference for licensing rules that promote free, open access to the spectrum. Rather than deriving revenue from subscribers, this class of firms earns revenue from advertisers and/or retail customers that sell good/services to customers via the Internet.

9 The valuations refer to an optimum amount of spectrum which is specified in (or can be deduced from) the scenarios designed for each service by Ofcom. Additionally, for some services there exists a minimum amount of lots (the service cannot be provided with less lots) or a maximum amount of lots (additional lots would be unnecessary under the current market conditions) as stated in Table 1, colum "desired amount of spectrum".
} 
Table 1 Characteristics of simulated bidders

\begin{tabular}{|c|c|c|c|c|c|}
\hline & Bidder & $\begin{array}{l}\text { Market } \\
\text { target }\end{array}$ & $\begin{array}{l}\text { View on the } \\
\text { market }\end{array}$ & $\begin{array}{l}\text { Desired amount } \\
\text { of spectrum }(\mathrm{MHz})\end{array}$ & $\begin{array}{l}\text { Bidder } \\
\text { "label" }\end{array}$ \\
\hline 1 & Secondary TV broadcaster & DTT (SD) & Conservative & $24-96$ & Weak \\
\hline 2 & Leading TV broadcaster & DTT (HD) & Conservative & $24-96$ & Weak \\
\hline 3 & $\begin{array}{l}\text { Leading TV } \\
\text { broadcaster }\end{array}$ & $\begin{array}{l}\text { DTT (SD)/MobM- } \\
\text { Media }\end{array}$ & $\begin{array}{l}\text { Unenthusiastic/ } \\
\text { Conservative }\end{array}$ & $8-96$ & Average \\
\hline 4 & $\begin{array}{l}\text { Incumbent mobile } \\
\text { operator }\end{array}$ & $\begin{array}{l}\text { MobComm/ } \\
\text { MobMMedia }\end{array}$ & $\begin{array}{l}\text { Unenthusiastic/ } \\
\text { Conservative }\end{array}$ & $8-96$ & Strong \\
\hline 5 & $\begin{array}{l}\text { Alternative mobile } \\
\text { operator }\end{array}$ & MobComm & Conservative & $8-96$ & Weak \\
\hline 6 & New entrant & MobComm & Optimistic & $8-64$ & Average \\
\hline 7 & New entrant & MobMMedia & Optimistic & $8-48$ & Strong \\
\hline
\end{tabular}

DTT digital terrestrial television — standard (SD) or high (HD) definition, MobMMedia mobile multimedia, MobComm mobile communications

a minimum value have been calculated according to the characteristics of the markets themselves, the position of each participant (incumbent/leading, established alternative/secondary operator or new entrant) and views on the future profitability of those markets (optimistic, conservative or unenthusiastic). Table 1 summarizes bidders' features. Obviously, the model does not try to capture every possible market player profile. However, the characteristics of the simulated participants listed in Table 1 match the description of some of the agents that would participate in a European auction of spectrum. This lends realism to the model, yielding more relevant results.

The right-hand column of Table 1 needs clarification. Taking into consideration valuation intervals made by participants, bidders have been classified into three groups, labeled as "strong", "average" and "weak". A priori, a strong bidder would bid high, whereas a weak bidder would submit modest bids. Note, however, that, as will be explained later, final values fluctuate within interval limits and, moreover, bids are not equal to values. Nevertheless, this classification will be conceptually helpful for the sake of analyzing different strategies. A summary of the simulated model tested in next section is described in Table 2.

\section{A Decision Bidding System for the Clock-Proxy Auction}

In auctions, as in games, finding an optimal strategy by enumeration is, in most cases, computationally unfeasible, and best response behavior is highly sensitive to participants' values and to the strategies used by other participants (Reeves et al. 2005). This problem is even more complex in intricate environments where bidders present both substitutes and complements among items, just as happens in spectrum license markets. As modeling such rational decision-making is extremely difficult, conventional mathematical models are inadequate. To deal with this problem, we assume bidders with bounded rationality using an evolutionary computation-based system that leads to intelligent bidding strategies and works as a decision support tool. This system learns from the environment and improves bidding behavior with experience. As a 
Table 2 Summary of the constrained simulated model

\begin{tabular}{|c|c|}
\hline Parameters & \\
\hline Auction format & Clock-proxy auction \\
\hline $\begin{array}{l}\text { Bandwidth of the total spectrum } \\
\text { to be auctioned }\end{array}$ & $96 \mathrm{MHz}$ \\
\hline $\begin{array}{l}\text { Types of bands in which the spectrum } \\
\text { is divided in }(\Omega)\end{array}$ & $m=3$ \\
\hline \multirow[t]{2}{*}{$\begin{array}{l}\text { Number of lots included in each } \\
\text { type of band }\end{array}$} & $\Omega_{1}=1(40 \mathrm{MHz})$ \\
\hline & $\begin{array}{l}\Omega_{2}=2(16 \mathrm{MHz}) \\
\Omega_{3}=3(8 \mathrm{MHz})\end{array}$ \\
\hline Number of bidders & 7 \\
\hline $\begin{array}{l}\text { Operators' value for each } \\
\text { item and package } \\
\text { (maximum value willing to } \\
\text { pay) }\end{array}$ & $\begin{array}{l}\text { A value from a normal } \\
\text { distribution between a } \\
\text { max. and a min. value } \\
\text { calculated according to } \\
\text { Ofcom's estimations }\end{array}$ \\
\hline
\end{tabular}

The model simulates an auction of a digital dividend portion in a European country using realistic parameters

result, it proposes for each type of bidder-strong, average and weak - the best bidding decision. To assess the quality of the recommended strategies, we carried out an experimental validation. Finally, we studied the auction outcome (spectrum allocation and seller's revenue) when all bidders behave according to the decision system eventually developed and compared it to the efficient outcome of the auction. ${ }^{10}$

\subsection{Developing a Decision Bidding System}

The clock-proxy is a combinatorial auction format with two phases: the clock phase and the proxy phase. The possible combinations of bidding strategies both in the clock and proxy phase are immense. Hence, specific assumptions have been made about bidders' behavior.

\section{Bidding in the Clock Phase}

We assume that bidders in the clock phase follow a limited straightforward bidding strategy. According to Ausubel and Milgrom (2002), bidders adopting this strategy bid in each round on the package that has the highest profit potential, as long as the potential profit is greater than some target amount. This strategy is implemented by the "semi-sincere strategy," as bidders shade their bids in the clock phase and only reveal a percentage of their personal value $(t)$. To test a wide range of strategies, the system implements this behavior for the following values of $t: 20,30,40,50,60$,

10 The strategy proposed by the genetic algorithm (GA) is, in fact, what should be expected that an informed rational bidder plays to try to maximize his/her expected profit. Hence, by simulating all bidders following this strategy the seller and the participants can have some hints about the auction outcome. 


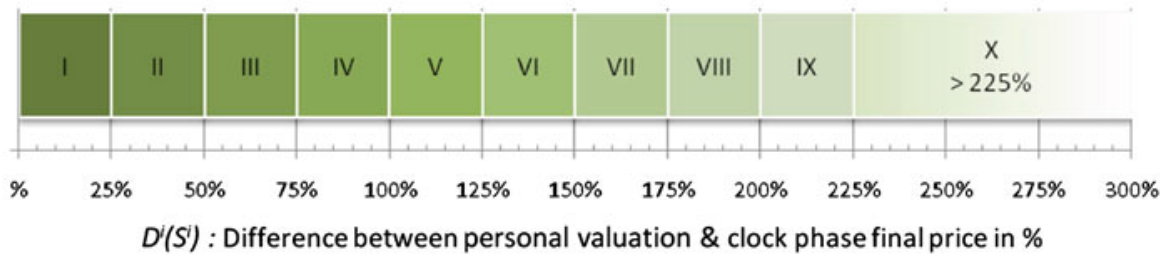

Fig. 2 Interval considered for choosing a strategy

70, 80 and $90 \%$. When developing the decision system, we assume that all bidders select the same value of $t$ and that it only changes from one experiment to another. Afterwards, for validating the system, the value of $t$ changes randomly among bidders in each run.

\section{Bidding in the Proxy Phase}

In the proxy phase, bidders submit a sealed bid for all packages they are interested in, and packages are priced by bidders instead of being assigned additive prices on individual lots as in the clock phase. For making their final bids, bidders take advantage of price discovery during the clock phase by bidding some value between the final clock price and their value. The number of possible bids might be enormous, which makes it impossible to test all of them. Hence, we propose several candidate strategies. The possible bids bidder $i$ can make for the package (or single item) $Q^{i}$, are calculated according to Eq. 5:

$$
P^{i}\left(Q^{i}\right)=\left[v^{i}\left(Q^{i}\right)-\hat{P}^{L}\left(Q^{i}\right)\right] g+\hat{P}^{L}\left(Q^{i}\right)
$$

where $v^{i}\left(Q^{i}\right)$ is the value for a specific package $Q^{i}$ (or single item), $Q^{i} \subset \Omega$ being the package (or single item) selected by bidder $i$. This value is the maximum amount bidder $i$ is willing to pay for $Q^{i} \cdot \hat{P}^{L}\left(Q^{i}\right)$ is the final clock price for the specific package $Q^{i}$ (or single item); and $g$ is a parameter which determines the different strategies to be tested: $0 \leq g<1$ with intervals of $1 / 10$. Deciding the final bids implies choosing the value of $g$ for each package. Hence, packages are classified in different intervals $\left(D^{i}\left(Q^{i}\right)\right)$ according to the difference between value and final clock price (see Eq. 6 and Fig. 2).

$$
D^{i}\left(Q^{i}\right)=\frac{\left[v^{i}\left(Q^{i}\right)-\hat{P}^{L}\left(Q^{i}\right)\right]}{\hat{P}^{L}\left(Q^{i}\right)}
$$

\subsection{Optimizing the Decision System by Means of Genetic Algorithms}

The goal of the decision system is to determine the best value of $g$ for each interval. This can be handled by a genetic algorithm (GA), which is a non-deterministic evolutionary computation technique, based on the mechanics of natural selection and 
natural genetics, which is recommended for searching solutions in dynamic, noisy and heterogeneous environments, according to Dasgupta and McGregor (1992) and Cobb and Grefenstette (1993). Moreover, GAs have been used in scientific literature devoted to auctions. Some examples are Andreoni and Miller (1995), Dawid (1999), Numnonda and Annakkage (1999), Wen and David (2001), Anthony and Jennings (2002, 2003), Cliff (2003), Saez et al. (2007) and Sun and Vora (2009).

Essentially, a GA is an iterative procedure that maintains a population of structures that are candidate solutions for specific domain challenges. During each generation, the structures in the current population are rated for their effectiveness as solutions. Based on these evaluations, a new population of candidate structures is formed, using specific "genetic operators", such as reproduction, crossover, and mutation. Crossover and mutation, which represent solutions, are simple procedures for individuals to modify their genetic code to evolve and improve in the following generations. Crossover allows an individual to create a new strategy by borrowing parts of previously successful solutions. Mutation allows an individual to make small modifications in past solutions in hopes of finding something better. For further details of how this algorithm works, see Mitchell (1998).

The developed GA used in this study is an improved version of the one described in Mochon et al. (2009). A flow-chart diagram of how the system works can be seen in Fig. 3. The aim of the GA is to find a set of bidding strategies that maximize the payoff for the bidder; the GA then maps the strategic variable $g$ onto the chromosome, and each gene represents the recommended strategy for each interval $\left(D^{i}\left(Q^{i}\right)\right)$ (see Fig. 4). The possible values of each gene, or allele, range from 0 to 9 (base 10). The population is made of 50 candidate strategies, which are randomly initialized. There is no information exchange between bidders other than the amount of profit, which is the fitness value. In a competitive complex game like this one, playing a specific strategy can yield different outcomes, depending on rivals' preferences and strategies played. To overcome this problem we have decided to evaluate each individual in 100 auctions with a predefined set of strategies arbitrarily generated for the rest of the participants. The fitness value of that generation is the average profit obtained by this bidder during these 100 auctions. This predefined set of $g$ values stays constant until the last generation to guarantee that identical genotypes lead to the same fitness during evolution. Once a population of individuals with calculated fitness values arises, the tournament selection operator is applied (10\% of the population is selected for each tournament). After the selection, a uniform crossover is applied to all the selected individuals, and finally, the mutation operator is instituted, changing $15 \%$ of the genetic material randomly. At this point, the new population is created, and the process starts again with the evaluation procedure. The GA reaches the stop criteria after 100 generations, and we have run 10 different experiments for each value of $t$ from the clock phase strategy. This is done to find a robust bidding pattern that is able to maximize average profits in many different situations. The developed GA uses nonoverlapping populations and elitism is on, meaning that the best individual from each generation is carried over to the next generation.

All the parameters used in the GA were determined empirically, based on the recommendations found in Goldberg (1989), and are summarized in Table 3 for replication purposes. Nevertheless, when the algorithm was tested with other parameters 


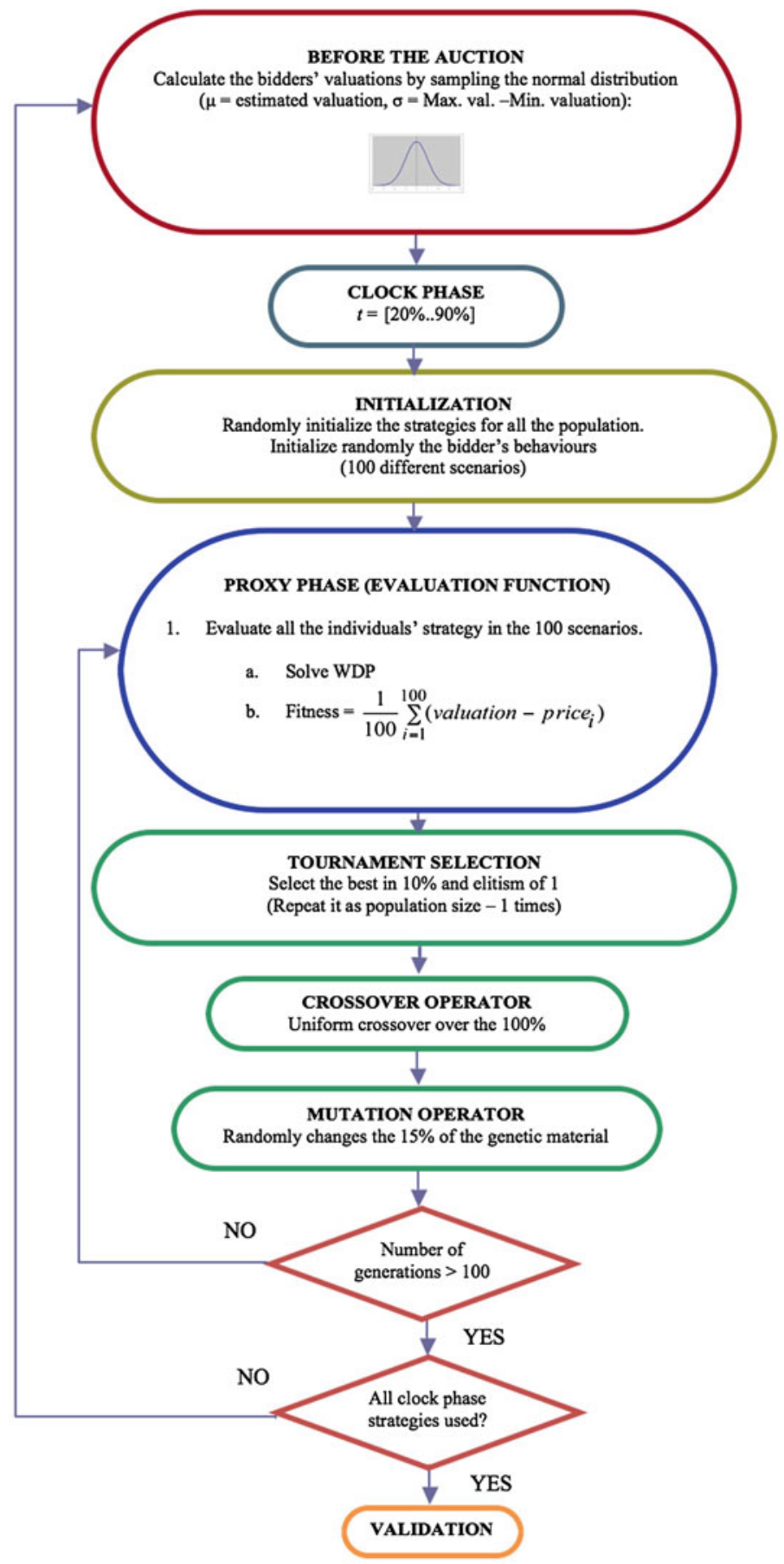

Fig. 3 Flow-chart diagram for the developed system 


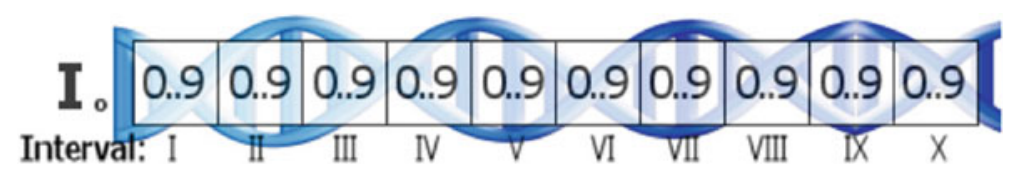

Fig. 4 Scheme of chromosome which contains the bidding strategies used by the GA for each interval

Table 3 GA Parameters used

\begin{tabular}{ll}
\hline GA Parameters & Values \\
\hline Number of generations & 100 \\
Population size & 50 \\
Chromosome length & 10 \\
Alleles & 1.10 \\
Selection operator & Tournament, 10\% \\
Crossover operator & Uniform, 100\% \\
Mutation rate & $15 \%$ \\
Elitism & On, 1 individual \\
\hline
\end{tabular}

(population size, mutation rates and selection types), the results found were similar (only minor differences in outcomes were found).

\subsection{Validating the Decision System}

When the GA is finished, a vector with the recommended strategies for each interval and type of bidder is proposed. These strategies is what should be expected that an informed rational bidders plays in order to maximize his/her expected profits. To support the results obtained, an exhaustive validation test bed was carried out, and to provide more robustness, the following variables that were fixed previously are now detached:

- In the clock phase, each bidder randomly selects the value of $t$ (from 20 to $90 \%$ ), which differs among bidders in each run.

- In the proxy phase, all bidders except the considered one randomly select their strategy vector for each run.

The candidate solutions offered by the system for each interval were verified looking at the average outcome obtained by the selected bidder under two assumptions. Under the first, the bidder follows the final vector strategies proposed by the GA for each interval. Under the second, the bidder behaves just like the other bidders; that is, he randomly selects the value of $g$ [this is similar to the random walk hypothesis for stock market prices Cootner (1964)]. Then the profits obtained under both assumptions are compared. 
Table 4 Strategy proposed by the GA for each interval and type of bidder

\begin{tabular}{|c|c|c|c|c|c|c|c|c|c|c|}
\hline & I & II & III & IV & $\mathrm{V}$ & VI & VII & VIII & IX & $X$ \\
\hline Strong & 0.4 & 0.3 & 0.4 & 0.4 & 0.4 & 0.5 & 0.5 & 0.4 & 0.5 & 0.5 \\
\hline Average & 0.3 & 0.4 & 0.5 & 0.5 & 0.5 & 0.5 & 0.6 & 0.6 & 0.5 & 0.6 \\
\hline Weak & 0.8 & 0.8 & 0.8 & 0.8 & 0.8 & 0.8 & 0.8 & 0.7 & 0.8 & 0.9 \\
\hline
\end{tabular}

\section{Analysis of the Results}

The experiments conducted with the system developed under the selected environment produced a large number of results. These results illuminate several topics:

\subsection{About Bidding Strategies}

We assume bidders with bounded rationality following a limited straightforward bidding strategy in the clock phase. Thus, the GA must search for the best strategy per type of bidder per interval in the proxy phase (value of $g$ ). This search implies a strategic decision that takes into consideration that a tradeoff exists between the probability of winning a lot and the potential for earning profits. If the GA proposes a strategy close to 0.9 , the bidder has more chances to be awarded with some package, but profits would be lower. On the other hand, if the GA proposes a strategy close to 0.1 , the likelihood is less that the bidder will win a package, but if it happens, he will earn higher profits. After all the simulations are done, the strategy vector that the GA proposes for the strong, average and weak bidder for each interval is represented in Table 4. Hence, to calculate the final bid for each package, the bidder will first determine the interval it belongs to. Then the $g$ value proposed by the GA is included in Eq. 5 to obtain the bid. The values of $g$ proposed for each interval are the strategies that yield higher average profits for each type of bidder.

Because of the structure of his/her values, the strong bidder ${ }^{11}$ has many chances to win some package (or single item). Hence, bidding very close to his/her personal value would reduce his/her profits. The best strategies the system proposes for this bidder are always between 0.3 and 0.5 . Moreover, the value of $g$ tends to increase as the interval increases. The strategy that the system proposes for the average bidder ${ }^{12}$ is quite similar to the strong one. He also has quite a lot of opportunities to win some package (or single item). His/her best strategy is in the range from 0.3 to 0.6 . For this bidder, the value of $g$ also increases as the interval grows. Finally, the weak bidder ${ }^{13}$ is unlikely to be awarded with a package (or single item). Therefore, his/her best strategy in the proxy phase is to bid very close to his/her personal value for any given interval.

\footnotetext{
11 In this section, the chosen strong bidder is an incumbent mobile operator (number 4 in Table 1).

12 In this section, the chosen average bidder is a new entrant interested in operating in the mobile communications market (number 6 in Table 1).

13 In this section, the chosen weak bidder is a leading TV broadcaster interested in broadcast HD channels (number 2 in Table 1).
} 
Table 5 Results obtained with GA and random strategies

\begin{tabular}{llll}
\hline & GA strategy & RND strategy & Difference $(\%)$ \\
\hline Strong bidder & & & \\
Total experiments & 100,000 & 100,000 & \\
Percentage of experiments with positive profits & 83.80 & 88.38 & -5 \\
Average profit (in 1MM $€$ ) & 117 & 66 & 77 \\
Average profit when earning at least a lot (in 1MM€) & 139 & 74 & 87 \\
Average bidder & & & \\
Total experiments & 100,000 & 100,000 & -8 \\
Percentage of experiments with positive profits & 63.33 & 69.21 & 72 \\
Average profit (in 1MM $€$ ) & 79 & 46 & 88 \\
Average profit when earning at least a lot (in 1MM€) & 125 & 66 & 126 \\
Weak bidder & & & 123 \\
Total experiments & 100,000 & 100,000 & -1 \\
Percentage of experiments with positive profits & 1.79 & 0.79 & 0.32 \\
Average profit (in 1MM $€$ ) & 0.72 & 41 & \\
Average profit when earning at least a lot (in 1MM€) & 40 & & \\
\hline
\end{tabular}

In all experiments, bidders follow a limited straightforward bidding strategy in the clock phase. In the proxy phase the results are compared for two strategies: bidders select the value of $g$ according to the GA versus a random selection of the value of $g$ (RND).

Hence, the decision support system discovers for this bidder strategies that range from 0.7 to 0.9 .

\subsection{About the Effectiveness of the GA}

Strategies proposed by the decision system in the proxy phase are scored against a random selection of $g$ for all bidder types tested. Table 5 shows the results obtained by each type of bidder when they follow the GA strategy versus a random (RND) decision (in the clock phase bidders always follow a limited straightforward bidding strategy). This validation was run 100,000 times in an environment where participants' bids differ from one run to another. As said previously, bidders' values are bounded between a minimum and a maximum value consistent with a realistic hypothesis. A value between these two is selected for each run according to a normal distribution function. Afterwards, the percentage of the personal value up to which bidders are interested in bidding on in the clock phase (value of $t$ ) is selected randomly.

The results show that the system developed is able to offer a vector of strategies for each type of bidder that markedly increases his/her average profit. The strong bidder improves his/her average profits by $77 \%$; the average bidder by $72 \%$; and the weak bidder by $123 \%$. Moreover, the non-parametric Wilcoxon rank-sum test reveals that the differences in average profits obtained by each behavior is statistically significant ( $p=0.0$ ) for the bidders considered.

For the strong and average bidder, the strategy proposed by the system yields higher average profits, although the number of times that the bidder earns positive profits is 
Table 6 Seller's income progress

\begin{tabular}{|c|c|c|}
\hline & $\begin{array}{l}\text { Sellers' average } \\
\text { income (in } 1 \mathrm{MM} € \text { ) }\end{array}$ & $\begin{array}{l}\text { Difference respect to } \\
\text { efficient outcome (\%) }\end{array}$ \\
\hline Efficient outcome & 2,126 & \\
\hline All bidders RND strategy in proxy phase ${ }^{\mathrm{a}}$ & 1,653 & -22.24 \\
\hline Weak bidder GA strategy in proxy phase ${ }^{a}$ & 1,640 & -22.87 \\
\hline Average bidder GA strategy in proxy phase $\mathrm{a}^{\mathrm{a}}$ & 1,622 & -23.72 \\
\hline Strong bidder GA strategy in proxy phase ${ }^{a}$ & 1,610 & -24.27 \\
\hline All bidders GA strategy in proxy phase ${ }^{a}$ & 1,535 & -27.81 \\
\hline
\end{tabular}

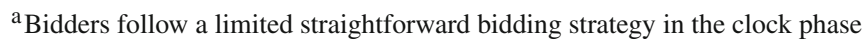

slightly lower ( 5 and $8 \%$ respectively). This means that the recommendation system chooses more risky strategies to try to increment potential profits. Hence, if we only consider the average profits the bidder earns when he/she wins some items, the discovered strategy yields even better results. Bidders improve their average profits by 87 (strong bidder) and $88 \%$ (average bidder). For the weak bidder, the system proposes a different strategy. As he has not many chances to win, the GA prefers strategies which involve higher winning probability and lower potential profits (less risk). Thus, when comparing both results for this bidder, the recommended strategy wins more times, although the average profits when he wins some lots are similar.

Playing the proposed strategy also affects the seller's outcome. Table 6 shows the seller's income progress as bidders use the recommended strategy. The results reveal that the sellers' income decreases with respect to the efficient outcome as bidders learn to bid with the developed system, and the reduction is higher as the bidder gets stronger.

\subsection{Auction Outcome under GA-Based Strategies}

Another important aspect to analyze is how the radio spectrum is allocated among bidders when they all follow a limited straightforward bidding strategy in the clock phase and behave according to the GA strategies in the proxy phase. To this end, we considered the "bidders label" shown in Table 1.

Figure 5 shows how the entire spectrum auctioned $(96 \mathrm{MHz})$ is distributed among types of bidders. The results show that the 2 strong bidders earn $51.02 \%(48.97 \mathrm{MHz})$ of the total spectrum, the average bidder $42.36 \%(40.66 \mathrm{MHz})$ and the weak bidders only win $6.63 \%(6.36 \mathrm{MHz})$. With this behavior, the seller's average income is $1.535 \mathrm{MM}$ Euros, a reduction of $7.16 \%$ in respect to the same value if all bidders select the value of $g$ randomly (see Table 6).

\subsection{About the Efficient Outcome of the Clock-Proxy Auction}

To study the clock-proxy auction outcome in terms of revenue maximization and efficient allocation, we calculated the efficient outcome of the auction (the assignment that maximizes total value). When bidders follow the GA bidding strategy, the seller's 


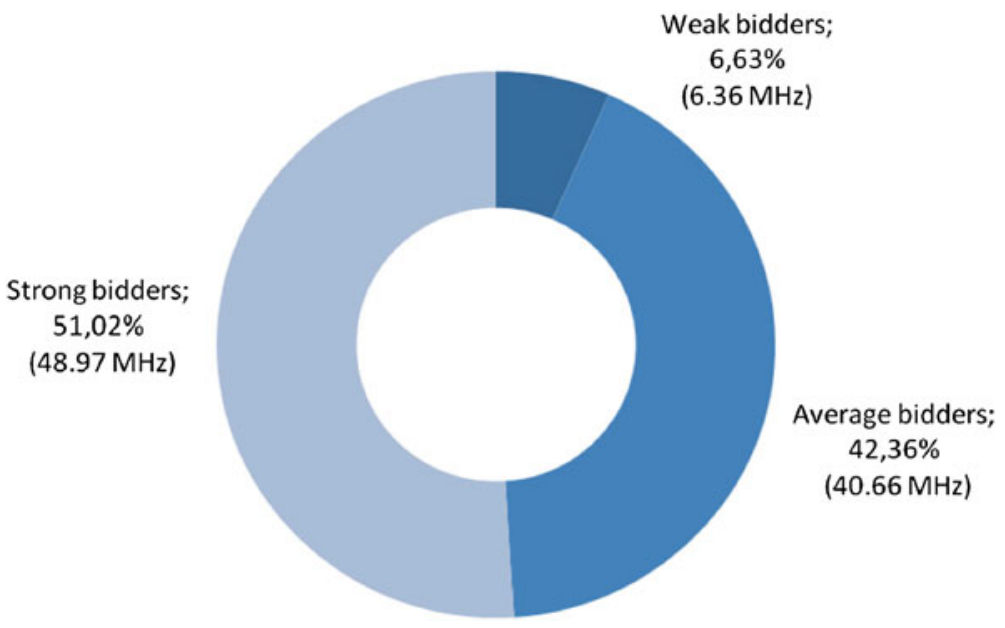

Fig. 5 Final allocation of the radio spectrum among types of bidders (all bidders playing GA strategies)

Table 7 Spectrum Allocation

\begin{tabular}{lllc}
\hline & $\begin{array}{l}\text { Efficient allocation } \\
(\mathrm{MHz})\end{array}$ & $\begin{array}{l}\text { All bidders GA } \\
\text { strategy in proxy } \\
\text { phase }(\mathrm{MHz})\end{array}$ & Difference (MHz) \\
\hline Three weak bidders & 1.03 & 6.37 & 5.34 \\
Two average bidders & 38.59 & 40.66 & 2.07 \\
Two strong bidders & 56.38 & 48.97 & -7.41 \\
Total Spectrum & 96.00 & 96.00 & \\
\hline
\end{tabular}

income decreases by $27.80 \%$ in respect to the efficient outcome (see Table 6). The divergence between the efficient outcome and the outcome obtained when bidders make their decisions based on the GA in the proxy phase are probably influenced by the pricing rule selected (pay-your-bid). The advantage of this pricing rule is that is simple for bidders to understand and implement, but bidders must focus on the bidding strategy to maximize their profits. Hence, using the GA decision system improves their profits as they learn to play their best strategies, which reduce the seller's income. Nevertheless, these differences would have been probably smaller using the second-price rule, or the bidder-optimal core pricing rule, as the pricing rule provides incentive for truthful bidding and bidders can concentrate on valuing the packages rather than focusing on a bidding strategy (Ausubel and Cramton 2008).

Finally, the efficient allocation of the radio spectrum was also been compared with respect to the outcome when all bidders make their decisions based on the GA (see Table 7). The distribution among bidders of the total spectrum does not reflect significant differences, as only $7.72 \%$ of the total spectrum is reallocated $(7.41 \mathrm{MHz}$ out of $96 \mathrm{MHz}$ ). The average bidders only earn 2.07 additional $\mathrm{MHz}$ with the GA strategies. The weak bidders are the ones that take more advantages of the GA decision system. As these bidders have the lowest valuations, focusing on their bidding strategies yields 
important improvements (5.34 additional MHz). For strong bidders, the GA proposes strategies that reduce their chances to win but increases profits, so they lose $7.41 \mathrm{MHz}$.

\section{Conclusions and Future Work}

The digital dividend award process is a key decision that governments worldwide must face in the coming years. Using combinatorial auctions to allocate radio spectrum is becoming a frequently used mechanism in many countries, as it represents a transparent and efficient allocation process. In this study, we have simulated an auction of a portion of the digital dividend. The format selected for the auction was the clock-proxy auction; studies in the auction field have advised using this format and Ofcom is considering it as a candidate auction formats. Moreover, we have designed a realistic model for bidders' characteristics and preferences_-including complements and substitute licenses - that could fit in most European countries.

The main goal of this study has been to analyze the clock-proxy auction as a selling mechanism for the spectrum license market. To this end, the behavior of three types of bidders with different expected values that characterize them as strong, average and weak bidders was studied. These bidders represent three particular types of companies who will most probably be present in any European auction that sells spectrum licenses derived from the digital dividend.

We assume bidders with bounded rationality following a limited straightforward bidding strategy in the clock phase. Then a search for the best strategies in the proxy phase was performed using a GA-based system. The GA explores several candidate strategies which depend on the parameter $g$ and the difference between the bidders' value and the final clock price for each item or package. The values of this difference were grouped into ten different intervals. The GA is in charge of discovering an optimal value of $g$ for each interval - that is, a vector of strategies that yields higher average profits to the selected bidder. To validate the strategies proposed by the GA, an exhaustive test bed was run. For this, average outcomes for the bidder that follows GA-based strategies have been compared with those obtained when the bidder behaves according to a random selection of strategies in the proxy phase. For all the tests done, the proposed solution always yields higher average profits. Finally, we calculated the efficient outcome of the auction and compared it to our results. The seller's income decreases by $27.80 \%$ in respect to the efficient outcome when all bidders make their bidding decisions according to the GA. These differences are probably apparent because of the pricing rule selected: pay-your bid. With this pricing rule, the bidding strategy plays a key role, so bidders take advantage of the GA decision system developed to maximize their profits. An interesting work for the future would be to compare these differences when the bidder-optimal core pricing rule is selected. Regarding the efficient allocation of the spectrum, there were no significant differences found in the distribution of the spectrum among bidders, which suggests the clock proxy auction is an adequate mechanism for allocating licenses in this market.

In intricate games such as combinatorial auctions with complex structures of preferences, an optimal strategy for all bidders is unlikely to be found in any environment. Nevertheless, evolutionary computational techniques are an effective tool for 
carrying out meticulous simulation studies and discovering bidding patterns in particular models. In this sense, the results gain relevance if a realistic model is assumed and potential participants can take advantage of this outcome to support their future decisions. Besides, these techniques are also an interesting tool for studying auction outcomes.

Acknowledgments The authors want to thank Prof. Lawrence M. Ausubel, Prof. Vijay Krishna and an anonymous reviewer for their valuable suggestions. This article has been financed by the Spanish research MCyT project MSTAR, Ref: TIN2008-06491-C04-03/TIN.

\section{References}

Andreoni, J., \& Miller, J. H. (1995). Auctions with artificial adaptive agents. Games and Economic Behaviour, 10, 39-64.

Anthony, P., \& Jennings, N. R. (2002). Evolving bidding strategies for multiple auctions. In Proceedings of the 15th European conference on artificial intelligence (pp. 178-182).

Anthony, P., \& Jennings, N. R. (2003). Developing a bidding agent for multiple heterogeneous auctions. ACM Transactions on Internet Technology, 3(3), 185-217.

Ausubel, L. M., \& Cramton, P. (2008). Bidder information package for 2009 New York slot auctions. Appendix on winner determination and pricing, power auctions LLC.

Ausubel, L. M., Cramton, P., McAfee, P., \& McMillan, J. (1997). Synergies in wireless telephony: Evidence from the broadband PCS auctions. Journal of Economics and Management Strategy, 6(3), 497-527.

Ausubel, L. M., Cramton, P., \& Milgrom, P. (2005). System and method for a hybrid clock and proxy auction, International Patent Application No. PCT/US2004/037037.

Ausubel, L.M., Cramton, P., \& Milgrom, P. (2006). The Clock-proxy auction: A practical combinatorial auction design. In P. Cramton., Y. Shoham., \& R. Steinber (Eds.), Combinatorial Auctions (pp. 115-138). Cambridge, USA: MIT Press.

Ausubel, L. M., \& Milgrom, P. (2002). Ascending auctions with package bidding. Frontiers of Theoretical Economics, 1(1), 1-42.

Avenali, A., \& Bassanini, A. (2007). Simulating combinatorial auctions with dominance requirement and loll bids through automated agents. Decision Support Systems, 43, 211-228.

Bulow, J., \& Klemperer, P. (2009). Why do sellers (usually) prefer auctions? American Economic Review, 99(4), 1544-1575.

Bykowsky, M. M., Olson, M., \& Sharkey, W. W. (2010). Efficiency gains from using a market approach to spectrum management. Information Economics and Policy, 22(1), 73-90.

Cliff, D. (2003). Exploration in evolutionary design of online auction market mechanisms. Electronic Commerce Research and Applications, 2(2), 162-175.

Cobb, H. G., \& Grefenstette, J. J. (1993). Genetic algorithms for tracking changing environments. In Proceedings of the 5th international conference on genetic algorithms (pp. 523-529).

Cootner, P. H. (1964). The random character of stock market prices. Cambridge, MA: MIT Press.

Cramton, P. (2002). Spectrum auctions. In Handbook of telecommunications economics, Chapter 14 (pp. 605-639). Amsterdam: Elsevier Science B.V.

Cramton, P. (2007). How best to auction oil rights. In H. Macartan, D. S. Jeffrey, \& E. S. Joseph (Eds.), Escaping the resource curse. (pp. 114-151). New York: Columbia University Press.

Dasgupta, D., \& McGregor, D. R. (1992). Nonstationary function optimization using structured genetic algorithm. In Proceedings of PPSN II (pp. 145-154).

Dawid, H. (1999). On the convergence of genetic learning in a double auction market. Journal of Economic Dynamics \& Control, 23, 1545-1567.

Day, R. W., \& Raghavan, S. (2007). Fair payments for efficient allocations in public sector combinatorial auctions. Management Science, 53(9), 1389-1406.

Feijóo, C., Gómez-Barroso. J. L., \& Mochon, A. (2009). Reforms in spectrum management policy. In I. Lee (Ed.), Handbook of research on telecommunications planning and management for business (pp. 33-47). Hershey: IGI Global.

Goldberg, D. E. (1989). Genetic algorithm in search, optimization and machine learning. Reading, MA: Addison-Wesley Publishing Company, Inc. 
Hailu, A., \& Thoyer, S. (2010). What format for multi-unit multiple-bid auctions? Agent-based simulation of auction performance and nonlinear bidding behaviour. Computational Economics, 35, 189-209.

Mitchell, M. (1998). An introduction to genetic algorithms. Cambridge, Mass: MIT Press.

Mochon, A., Saez, Y., Isasi, P., \& Gómez-Barroso, J. L. (2009). Testing bidding strategies in the clock-proxy auction for selling radio spectrum: A genetic algorithm approach. In Proceedings of IEEE congress on evolutionary computation (pp. 2348-2353).

Numnonda, T., \& Annakkage, U. D. (1999). Optimal power dispatch in multimode electricity market using genetic algorithm. Electric Power Systems Research, 49(3), 211-220.

Ofcom, (2006). Digital dividend review. Document consulting on the proposed approach to the award of the digital dividend spectrum (470-862 MHz). United Kingdom Office of Communications. http:// www.ofcom.org.uk/consult/condocs/ddr/statement/.

Ofcom (2007). Digital dividend review: A statement on our approach to awarding the digital dividend. United Kingdom Office of Communications. http://www.ofcom.org.uk/consult/condocs/ddr/ statement/.

Parkes, D. C. (1999). iBundle: An efficient ascending price bundle auction. In Proceedings of the 1st ACM conference on electronic commerce (pp. 148-157).

Parkes, D. C., \& Ungar, L. H. (2000a). Iterative combinatorial auctions: Theory and practice. In Proceedings of the 17th national conference on artificial intelligence (pp. 74-81).

Parkes, D. C., \& Ungar, L. H. (2000b). Preventing strategic manipulation in iterative auctions: Proxy agents and price-adjustment. In Proceedings of the 17th national conference on artificial intelligence (pp. 82-89).

Reeves, D. M., Wellman, M. P., MacKie-Mason, J. K., \& Osepayshvili, A. (2005). Exploring bidding strategies for market-based scheduling. Decision Support Systems, 39, 67-85.

Saez, Y., Mochon, A., Gomez-Barroso, J. L., \& Isasi, P. (2008). Testing BOI and BOB algorithms for solving the winner determination problem in radio spectrum auctions. In Proceedings of the 8th international conference on hybrid intelligent systems (pp.732-737).

Saez, Y., Quintana, D., Mochon, A., \& Isasi, P. (2007). Effects of a rationing rule on the Ausubel auction: A genetic algorithm implementation. Computational Intelligence, 23(2), 221-235.

Sandholm, T. (2002). Algorithm for optimal winner determination in combinatorial auctions. Artificial Intelligence, 135, 1-54.

Stone, P., Schapire, R. E., Littman, M. L., Csirik, J. A., \& McAllester, D. (2003). Decision-theoretic bidding based on learned density models in simultaneous, interacting auctions. Journal of Artificial Intelligence Research, 19, 209-242.

Sun, Y., \& Vora, P. (2009). Auctions and differential pricing: Optimal seller and bidder strategies in second-chance Offers. Computational Economics, 34, 243-271.

Wellman, M. P., Reeves, D. M., Lochner, K. M., \& Vorobeychik, Y. (2004). Price prediction in a trading agent competition. Journal of Artificial Intelligence Research, 21, 19-36.

Wen, F. S., \& David, A. K. (2001). Strategic bidding for electricity supply in a day-ahead energy market. Electric Power Systems Research, 59(3), 197-206. 